\title{
Psicanálise e Educação: um tratamento possível para as queixas escolares
}

\author{
Nádia Laguárdia de Lima' \\ Ronaldo Sales de Araújo' \\ Eduardo Pio de Souza' \\ Allana Fernanda Gonçalves Dias' \\ Carolina Albuquerque Barbosa' \\ Raquel Gonçalves Silveira Alves' \\ Karina Maciel Nihari' \\ Nayara Serrano Barcelos Marchi'
}

'Universidade Federal de Minas Gerais (UFMG), Belo Horizonte/MG - Brasil

RESUMO - Psicanálise e Educação: um tratamento possível para as queixas escolares. Este artigo apresenta uma reflexão teórica decorrente de um trabalho realizado com professores do ensino fundamental em uma escola pública. Foi utilizada, como metodologia de trabalho, a conversação de orientação psicanalítica, apoiada pela ética do desejo e da responsabilização. As conversações tiveram como tema central as dificuldades encontradas pelos professores em suas práticas docentes. Os professores elegeram três principais impasses para a sua prática educativa: a família, a sexualidade e as políticas públicas. Com base na teoria dos discursos e na tríade temporal proposta por Lacan: o instante de ver, o tempo de compreender e o momento de concluir, o artigo apresenta uma reflexão sobre os efeitos da oferta da palavra aos professores na escola.

Palavras-chave: Psicanálise. Escola. Conversação.

ABSTRACT - Psychoanalysis and Education: a possible treatment for school complaints. This paper presents a theoretical reflection on a study conducted with elementary school teachers in a public school. It was applied Psychoanalytic orientation on conversations as a work methodology, supported by ethics of desire and accountability. The conversations had a main theme, which consisted on the difficulties confronted by teachers in their teaching practice. Teachers have elected three main deadlocks over their educational practice: family, sexuality and public policies. Based on Speech Theory and Temporal Triad proposed by Lacan - instant of seeing, time of understanding and moment of concluding - the author brings up a reflection on speech offer effects on elementary school teachers in a public school. Keywords: Psychoanalysis. School. Conversation.

Educação \& Realidade, Porto Alegre, v. 40, n. 4, p. 1103-1125, out./dez. 2015.1103 http://dx.doi.org/10.1590/2175-623645088 


\section{Introdução}

Este artigo apresenta uma reflexão teórica acerca de um trabalho realizado em uma escola de ensino fundamental da rede pública de Minas Gerais, explicitando a metodologia utilizada e sua base teórica, num esforço de formalização dessa experiência. O projeto surgiu a partir de um convite feito pela coordenação da escola ao Departamento de Psicologia da Universidade. A escola em questão possui um projeto que contempla o diagnóstico e o tratamento das dificuldades escolares de cunho pedagógico. O encaminhamento para a psicologia normalmente é feito quando a escola considera que as dificuldades apresentadas pelos alunos e professores superam as possibilidades de intervenção no plano puramente pedagógico.

A instituição escolar, na atualidade, é claramente marcada por uma grave crise de âmbito mundial. A violência, as manifestações da sexualidade, a recusa da escola, a perda da autoridade dos professores, a indisciplina, a agitação e o desinteresse pela aprendizagem escolar são alguns dos problemas presentes nas escolas. Os métodos educacionais tradicionais mostram-se, muitas vezes, ineficazes para solucionar estes problemas. No entanto, o encaminhamento para o psicólogo normalmente é feito segundo um modelo tradicional e equivocado de intervenção clínica, que visa diagnosticar e tratar individualmente o aluno problema, reforçando a sua segregação e exclusão social.

O profissional que trabalha no campo da psicanálise aplicada tem o compromisso ético de mostrar a eficácia da sua prática clínica na instituição em que atua. Nesse sentido, a sua prática deve ser acompanhada da revisão constante de seus instrumentos metodológicos e conceituais, permitindo a formalização de sua experiência. A instituição escolar tem uma função educativa. Assim, respeitando essa especificidade e reconhecendo a distinção entre a psicanálise e a educação, a nossa questão é: de que forma o psicanalista pode contribuir para a formação crítica e reflexiva daqueles envolvidos no processo de ensino/ aprendizagem?

A intervenção clínica orientada pela psicanálise apresenta especificidades que a distinguem de outras práticas psicológicas, em função da concepção de sujeito que a sustenta. Freud nos ensinou que no ato educativo, além da transmissão de conhecimentos formais, ocorre outra modalidade de transmissão que escapa ao controle consciente, pois inclui o sujeito do inconsciente. Esta transmissão está para além do campo do saber universal e não há como se assegurar dela, assim como não existe uma forma de se prevenir contra os equívocos que a envolvem.

O conceito de inconsciente é, pois, fundamental para compreender as determinações que regem a vida de um sujeito. Ele interfere no processo de aprendizagem, é um saber que escapa ao sujeito e ao mesmo tempo o constitui. Um determinado conteúdo, veiculado pelo 
professor, afeta o sujeito de maneira particular, causando nele efeitos e impressões que não são previsíveis. Uma determinada matéria pode causar no aluno embaraços, inibições, deturpações, ou, ao contrário, despertar o seu interesse. Assim, “[...] o efeito produzido por aquele que ensina escapa-lhe, posto que existe um saber do qual o sujeito nada sabe e, mesmo sendo desconhecido e estranho ao sujeito, pode sustentar o desejo tanto de saber, quanto de ensinar" (Ferreira, 1998, p. 144).

A psicanálise é um saber que interroga o mal-estar na cultura, na civilização, na educação. Ela defende a impossibilidade de uma total coerência e controle sobre o próprio discurso. Há um mal-entendido na comunicação humana, decorrente da condição da linguagem, que marca uma ruptura entre a palavra e o objeto. A psicanálise se propõe a escutar o que insiste em se repetir, o que falha, apontando para uma dimensão humana da ordem do inacabado e do imprevisível, que atesta uma impossibilidade radical, muitas vezes desconsiderada pelos educadores.

Freud não acreditava em um ideal de normalidade, nem de educação. Se a educação é necessária para a formação humana, persiste uma dimensão ineducável em todo sujeito, que aponta para o real ${ }^{1}$. As tentativas de erradicação desta dimensão acabam por promover sua irrupção de forma drástica e, por vezes, destrutiva.

A especificidade da psicanálise está em localizar o singular do sujeito, para além das ofertas identificatórias propostas pela cultura e pelo discurso da ciência, pois estas ofertas podem alienar o sujeito, reduzindo a sua dificuldade a um déficit, que resulta em sua segregação e exclusão social. Dessa forma, ela não defende tratamentos específicos para indivíduos que apresentam problemas de aprendizagem como portadores de deficiência, hiperativos ou disléxicos. Ela não opera com classificações de transtornos, nem com tratamentos padronizados. Se, na lógica capitalista, todos são iguais perante o consumo, o reconhecimento da dimensão subjetiva na dificuldade de aprendizagem impede que o sujeito seja tratado como um objeto. O que é visado não é o transtorno ou o déficit, mas o sujeito, em sua singularidade.

Uma das possibilidades de se trabalhar com uma orientação psicanalítica nas instituições escolares é, pois, ofertando espaços de fala aos sujeitos, sejam eles alunos, professores ou pais, para que, no deslizar dos significantes, se abram novas perspectivas de interpretação de uma situação, desfazendo identificações geradoras de impotência, e produzindo novas saídas. Espaços coletivos de discussão, conduzidos por uma pessoa orientada pela psicanálise, favorecem o acolhimento dos conflitos existentes em todo processo de aprendizagem, permitindo a solução de alguns impasses na transmissão pedagógica ou na relação professor/aluno.

Tendo em vista as considerações acima, elaboramos um projeto de extensão e apresentamos à escola. A nossa proposta foi a de realizar 
um trabalho com os professores, utilizando como metodologia de trabalho, a conversação de orientação psicanalítica. Com base na teoria dos discursos e na tríade temporal proposta por Lacan no texto sobre o tempo lógico e a asserção de certeza antecipada (1998): o instante de ver, o tempo de compreender e o momento de concluir, este artigo apresenta uma reflexão teórica sobre o trabalho realizado na escola.

\section{A Metodologia de Trabalho: a conversação com os professores}

A demanda inicial da escola era a de que atendêssemos trinta crianças com problemas escolares. Acreditamos que o alto número de crianças-problemas numa escola indica que há uma responsabilidade da escola pelas dificuldades apresentadas pelos alunos. Assim, ao invés de reforçar esse imaginário de que as dificuldades escolares estão sempre localizadas nos alunos, buscamos implicar todos os envolvidos no processo educativo da criança no fracasso escolar que ela apresenta. Tivemos como norte os seguintes questionamentos: Qual a implicação do professor na queixa que ele formula? De que forma cada professor subjetiva a dificuldade escolar?

Como as queixas referentes aos alunos eram formuladas pelos professores, a nossa proposta foi a de ofertar, para o grupo de professores, um espaço para a palavra. Para evitar uma resistência da escola ao nosso trabalho, buscamos atender parcialmente à sua demanda. Além deste trabalho, realizamos estudos de casos de oito crianças, selecionadas pelos educadores. Assim, organizamos duas equipes de trabalho. Uma que conduziria as conversações com os professores; e outra equipe que acompanharia as crianças na escola, observando as suas interações com os colegas e professores, além de escutá-las individualmente, realizando um diagnóstico clínico. O diagnóstico tinha como objetivo identificar se as dificuldades apresentadas pelas crianças eram da ordem de uma inibição, devido aos impasses na relação transferencial professor/ aluno, ou da ordem de um sintoma. No último caso, as crianças seriam encaminhadas para atendimentos fora da escola. Neste artigo, abordaremos o trabalho realizado com os professores na escola.

Foi utilizada, como metodologia de trabalho, a conversação de orientação psicanalítica com os professores. As conversações tiveram como tema central as dificuldades encontradas por eles em suas práticas docentes. No primeiro semestre, os professores elegeram três principais impasses para a sua prática educativa, que se transformaram nos temas das conversações do segundo semestre.

Diversos psicanalistas têm atuado nas instituições escolares, trabalhando com grupos de professores, funcionários ou alunos. As metodologias utilizadas pelos psicanalistas nas escolas recebem diferentes denominações, tais como rodas de conversa, grupos de reflexão

1106 Educação \& Realidade, Porto Alegre, v. 40, n. 4, p. 1103-1125, out./dez. 2015. 
ou conversação, como é possível localizar nos trabalhos publicados por autores que sustentam essa prática, como Cohen (2006), Besset (2007), Santiago (2010), Pereira (2012), Coutinho (2007) e Lacadée (2000), dentre outros. A leitura dos textos destes autores de orientação lacaniana nos mostra que, apesar de algumas diferenças metodológicas, eles são orientados pela ética da psicanálise, que visa alcançar, no espaço coletivo, o singular de cada um.

Faz-se necessário estabelecer, portanto, de forma criteriosa, os princípios éticos que sustentam tal prática, a metodologia proposta e os seus objetivos. Utilizamos a metodologia de conversação de orientação psicanalítica lacaniana, um dispositivo clínico elaborado por Miller (2010), apoiado pela ética do desejo e da responsabilização, que permite a aplicabilidade da psicanálise nas instituições. O sujeito se constitui na cultura, a partir de seu assujeitamento à linguagem. O sujeito procura se localizar no discurso para ocupar um lugar na relação com o $\mathrm{Ou}$ tro (considerado aqui como campo simbólico, da linguagem). Os laços sociais, portanto, se organizam através dos discursos. A instituição é estruturada como linguagem e se organiza em torno do real como impossível de simbolizar. A instituição oferece a construção de uma ficção necessária e o encontro de um saber que serve de apoio ao sujeito, para que ele possa dar conta da perda de gozo resultante do encontro do ser com a linguagem (Lacadée, 2000).

Rosa (2004), ao discutir a presença do psicanalista nas instituições destaca que o desafio é construir uma prática clínica que considere os laços sociais, expressos como laços discursivos na instituição, uma prática psicanalítica movida pela concepção de sujeito, na dimensão dos discursos. A prática psicanalítica desloca-se, então, entre dois âmbitos: elucidar o discurso e as práticas sociais - a fim de problematizar os modos como esses discursos afetam a subjetividade - e escutar o sujeito, elucidando os modos pelos quais é afetado (Rosa, 2004).

A conversação permite colher e intervir nos efeitos dos laços discursivos sobre os sujeitos. Se o inconsciente não é educável, as intervenções em contextos escolares precisam utilizar modelos estruturados para o desenvolvimento das atividades. Neste caso, a conversação, mesmo não sendo um dispositivo didático-pedagógico, tem uma estrutura que sustenta seus objetivos.

O dispositivo da conversação utilizado nas escolas tem como fundamento cada um autorizar-se como sujeito. Ninguém ocupa o lugar do mestre, o que permite que a palavra circule, favorecendo uma série de associações livres (Miller, 1998). Segundo Santiago, Miranda e Vasconcelos (2006), esse dispositivo tem na associação livre coletivizada o seu ponto de sustentação, pois ela permite que o objeto de estudo seja analisado a partir de uma multiplicidade de significantes. Trata-se de buscar localizar os pontos de condensação do mal-estar na cultura atual, abrindo brechas para que essas máximas impostas pela cultura sejam

Educação \& Realidade, Porto Alegre, v. 40, n. 4, p. 1103-1125, out./dez. 2015.1107 
questionadas por cada um no grupo. Visa ainda tocar o ponto de real de cada um, que vai além das suas ficções (Lacadèe, 2000). Mas, é preciso estar atento ao momento de abrir as comportas e também de fechá-las. Não se trata de um tratamento psicanalítico. Deve haver um corte, que marca o limite deste dispositivo e que precipita o momento de concluir. Esse corte se dá através do limite de encontros, acertado com o grupo de participantes, e também durante as conversações, intervindo na cadeia discursiva, como será visto. Cada sujeito é convidado a participar das conversações, essa decisão, além de individual, é motivada pelo desejo de falar (Santiago, Miranda; Vasconcelos, 2006).

O coordenador das conversações não sabe, a priori, o que surgirá das conversações. Ao convocar o outro para falar, surgem como produtos desse endereçamento, os significantes mestres que localizam o gozo de cada um, e que possibilitam algum reposicionamento diante de sua própria fala. O objetivo das conversações não é produzir um saber sobre o sujeito, mas permitir que cada sujeito produza um saber próprio sobre aquilo que $\mathrm{o}$ aflige. $\mathrm{O}$ coordenador opera a partir do não-saber, do furo no saber instituído, fazendo o outro falar e permitindo que emerja o gozo ${ }^{2}$, o mal-estar próprio à singularidade. Udenio (2004) destaca os limites que a palavra introduz, pois ela não traz um sentido comum a todos, mas comporta o sentido do particular. Ela permite que se olhe mais além dos sentidos comuns, alcançando o mal-entendido, o fora-do-sentido, que aparece como um detalhe para cada um. O furo no dizer, como ausência fundamental, é onde cada um pode captar algo nas entrelinhas do que se diz, onde se articula o real em sua singularidade. Nas conversações, não se busca, portanto, o consenso entre as pessoas, a coerência ou a concordância do grupo, mas especialmente as diferenças, as surpresas, os equívocos nas falas, os lapsos ou tropeços da linguagem, que abrem a via de acesso ao real de cada um.

Assim, definimos que quem conduziria os grupos deveria ser formado em psicologia, estar em processo de análise e em formação psicanalítica, para que ele pudesse sustentar a transferência, permitindo o surgimento da associação livre, na forma coletivizada. Como nos esclarece Lacan (1992), a transferência não ocorre como um laço à pessoa, mas sim com o significante que, dirigido ao analista, porta uma significação, um saber inconsciente. No deslizamento dos significantes, a fratura do discurso aparece, os equívocos e contradições denunciam a divisão do sujeito, e as identificações mostram a sua impossibilidade em traduzir o singular de cada um.

Estabelecemos um número determinado de encontros. Acreditamos que essa demarcação estabelece um limite para esse trabalho, que não pode ser interminável, além de favorecer a precipitação da fala das professoras a partir daquilo que as angustia.

A conversação com os professores coloca em evidência a existência de uma verdade que é própria de cada um, que não é toda universa-

1108 Educação \& Realidade, Porto Alegre, v. 40, n. 4, p. 1103-1125, out./dez. 2015. 
lizável. Ao invés de tentar excluí-lo, o discurso do analista reconhece o impossível, para que ele não inviabilize a ação educativa. Não desconsideramos a possibilidade de saídas coletivas, construídas pelo grupo, elas são por vezes, necessárias, mas, enfatizamos a construção de saídas que dizem respeito a cada um. Se o fracasso escolar é o resultado de um mau encontro entre o educador e o aluno, entre a escola o Estado, ou entre a família e a criança, como salienta Cohen (2006), apostamos na possibilidade de uma nomeação desse mal-estar que pode ocasionar uma saída desse impasse. A oferta da escuta pode levar o professor a localizar o seu desejo de transmitir, apagado pelas normas burocráticas. Causado pelo desejo, ele pode criar uma solução própria para tratar o real que insiste.

Formamos dois grupos, um com os professores do turno da manhã (grupo A) e o outro com os professores do turno da tarde (grupo B). O primeiro grupo contou com a participação de doze professores que tiveram uma frequência constante nos dois semestres. Alguns professores do segundo grupo não tiveram uma frequência regular. Cada grupo de conversação era conduzido por um mestrando em psicologia, acompanhado por dois alunos de graduação em psicologia, que faziam os registros das conversações.

A princípio, surgiu uma resistência por parte dos professores à nossa proposta, mas, a partir do esclarecimento do projeto, da abertura do espaço para a palavra, do estabelecimento da transferência e do surgimento dos primeiros resultados terapêuticos desse trabalho, a resistência deu lugar ao interesse crescente dos professores pela participação nas conversações, especialmente no primeiro grupo. Consideramos que alguns professores do grupo B se mantiveram resistentes ao trabalho devido à participação da supervisora da escola nesse grupo, que insistia em assumir a posição de liderança nas conversações, apesar das tentativas feitas pelo coordenador de impedir que ela ocupasse essa posição naquele momento.

As conversações tiveram como tema central as dificuldades encontradas pelas professoras (todas eram do sexo feminino) em suas práticas docentes. O projeto teve a duração de um ano e as conversações ocorreram quinzenalmente, totalizando dezesseis encontros. O tempo de duração do projeto foi acertado com a coordenação e com os professores da escola. No primeiro semestre, os temas foram livres. No segundo semestre, realizamos conversas temáticas, a partir dos principais temas levantados pelos dois grupos no primeiro semestre, que foram: sexualidade, família e políticas públicas. Os temas foram ratificados pelas professoras e a proposta de se realizar as conversações a partir desses temas foi prontamente aceita por todos.

Ao propor conversações temáticas, não buscamos definir um roteiro ou fechar uma pauta, na tentativa de alcançar um acordo consensual dentro do tema proposto. O tema proposto funciona como uma

Educação \& Realidade, Porto Alegre, v. 40, n. 4, p. 1103-1125, out./dez. 2015.1109 
Psicanálise e Educação

questão ou pergunta que impulsiona a associação livre e que pode tomar qualquer rumo ou destino. Concordamos com Santiago, Miranda e Vasconcelos (2006) ao afirmarem que pauta, conteúdo definido, roteiro pré-determinado não se consubstanciam em uma conversação, pois o que se busca é um falar dos próprios sujeitos que dela participam e ensinam a quem conversa com eles.

Os dois grupos tiveram percursos e resultados diferentes, como será visto. Utilizamos a teoria dos discursos de Lacan $(1992)^{3}$ para buscar elucidar os diferentes discursos presentes na escola, marcando a especificidade do discurso do analista e a possibilidade de se operar com ele nas instituições.

\section{Os Quatro Discursos na Instituição Escolar}

A proposta de se ofertar espaços para a palavra aos professores surge do pressuposto de que alguém só é sujeito na medida em que fala. Ao falar, sua divisão é exposta. O professor expõe, através de sua fala, as ficções que circulam e sustentam a instituição, mas também os significantes que lhe tocam de forma particular. Ele denuncia, ainda, o não-saber que o aflige e é surpreendido pelos equívocos e contradições em seu discurso. Longe de buscar uma coerência ou uniformidade no que se diz, a psicanálise acolhe as contradições que aparecem na fala como resultado da divisão subjetiva, pois elas são manifestações do inconsciente. Para Lacan (1992), cada discurso implica numa forma própria de operar com o real do gozo, mas, há sempre um impossível de calcular, um limite do discurso.

Podemos localizar os diferentes discursos nas falas dos professores. O discurso universitário tem como agente o saber, ele se sustenta na existência de um saber universal. A instituição escolar defende um saber científico que corresponde a uma verdade absoluta, inquestionável. O saber científico é utilizado para obturar a falta, a impossibilidade. $\mathrm{O}$ discurso universitário faz calar o outro, faz calar o subjetivo que perturba o modelo universal. Mas, o fracasso escolar aponta para um fracasso no discurso universitário, uma falha no modelo universal. Os educadores utilizam o saber científico para nomear os alunos, classificá-los, segundo parâmetros biológicos, tentando submeter o gozo a um saber universal. O que se oculta é que esse saber científico foi produzido por alguém e atende a interesses de comunidades de pessoas. O resultado disso é a perda da possibilidade de se refletir sobre as relações existentes entre as condições subjetivas, institucionais, sociais, políticas e econômicas, e a produção do fracasso escolar.

O discurso do mestre é o discurso mais constante nas falas das professoras. Ele opera sobre o real, numa tentativa de governá-lo, submetê-lo ao saber. O mestre busca apropriar-se do saber fazer do outro, ele apela para o discurso científico para tentar domar o real, controlá-

1110 Educação \& Realidade, Porto Alegre, v. 40, n. 4, p. 1103-1125, out./dez. 2015. 
-lo. Há aqui uma promessa de um saber sem furo. Mas, o fracasso escolar aponta para um impossível de governar, um real que não se submete ao saber.

O discurso histérico também se fez presente nas conversações. Lacan evidencia o paradoxo deste discurso, pois ao mesmo tempo em que o sujeito se coloca nas mãos do Mestre idealizado que ele mesmo cria, oferecendo-lhe seu sintoma como enigma a ser decifrado, em seguida o desmascara, apontando a sua impotência em produzir um saber que dê conta de tratar seu gozo. Ou seja, ao mesmo tempo em que faz crer que se submete ao Outro, ele domina a relação. Esse discurso aparece frequentemente nas falas dos educadores. Os professores buscam um mestre que possa elucidar ou erradicar as causas do mal-estar que aflige a educação. As professoras demandam dos psicólogos cursos de capacitação, para obturar o não saber que as angustia. No entanto, elas se queixam dos cursos até então oferecidos a elas, reclamando dos mestres que lhes ofereceram capacitação, apontando para a incapacidade deles em resolver as dificuldades no campo educacional.

Lacan (1998), ao apresentar o discurso do analista, nos mostra a possibilidade de se operar com este discurso para além do âmbito dos consultórios, nas diferentes instituições sociais. O discurso do analista, ao contrário dos demais, não visa dominar o real ${ }^{4}$, mas se coloca frente a ele. Ao ser demandado a responder com um saber sobre o outro, ou seja, a partir do discurso do mestre, o analista responde promovendo um giro discursivo, colocando-se no lugar de causa. Ele coloca o sujeito em posição de produzir um saber próprio sobre o seu mal-estar.

Nas conversações, cada professora pôde falar a partir da própria dificuldade, ocupando a posição de sujeito, que, enquanto tal, pode falar sobre seu mal-estar. A partir daí, em lugar de alienação ao saber do Outro, ela pode se apropriar de algum saber sobre o seu gozo. O professor busca a resposta do mestre, mas a partir do momento em que o coordenador das conversações não se coloca nesse lugar, cada sujeito pode encontrar novos significantes que lhes tocam, de forma singular. A prática de conversação visa operar onde o discurso do mestre e o científico falham, entretanto, ela só é possível, no espaço escolar, porque está em inter-relação com os demais discursos (Lima; Cunha, 2013).

\section{A Escuta dos Professores: os três tempos lógicos}

Lacan, no texto sobre $O$ tempo lógico e a asserção da certeza antecipada (1998), destaca a relação existente entre subjetividade e temporalidade. Trata-se de um esforço teórico de trabalhar a questão temporal nos domínios da dedução lógica. Os termos: instante de ver, tempo para compreender e momento de concluir, apresentados por Lacan, foram inicialmente utilizados por Freud, para descrever a economia da libido. As três modalidades de tempo indicam, para Lacan, uma tensão tempo-

Educação \& Realidade, Porto Alegre, v. 40, n. 4, p. 1103-1125, out./dez. 2015.1111 
ral, e o momento de concluir é pensado a partir do modelo da descarga, numa referência ao principio do prazer freudiano. $\mathrm{O}$ tempo operativo na análise, que inclui três dimensões, é coerente com a temporalidade lógica da constituição do sujeito. Segundo o autor, a modulação do tempo em todo e qualquer processo lógico inclui o sujeito em três escansões. Ele demonstra que os três tempos lógicos revelam uma descontinuidade tonal e apresentam uma modulação tal que, na passagem de um tempo para o posterior, o anterior é reabsorvido (Lacan, 1998). Ao apresentar o sofisma dos três prisioneiros, o autor pretende mostrar que, se o raciocínio que antecede uma decisão pode se elaborar numa lógica intersubjetiva (tempo para compreender), o momento de concluir (asserção do sujeito) se produz num instante de decisão em que o sujeito se desprende da suposição atribuída ao Outro. $\mathrm{O}$ ato do analista produz, no desenrolar das cadeias significantes da associação livre, uma descontinuidade no tempo que, incidindo sobre a atemporalidade do inconsciente, proporciona um limite para a análise. Sem pretender comparar o dispositivo clínico da conversação com o processo de análise, buscaremos destacar, para a nossa reflexão, três tempos lógicos no movimento das conversações.

\section{O Instante de Olhar}

Partimos do instante de olhar. No primeiro semestre, buscávamos conhecer quais eram as maiores dificuldades que as professoras vivenciavam em suas práticas docentes. Essa pergunta desencadeou uma série de respostas que apontavam para problemas sempre externos aos professores. Destacamos a predominância do discurso histérico, marcado pela insatisfação. As professoras assumiam uma posição de impotência diante das dificuldades apresentadas pelos alunos, responsabilizando especialmente as famílias dos alunos pelo fracasso escolar. Foram também frequentes as queixas com relação às políticas públicas educativas, mostrando os seus equívocos e contradições. Falavam de uma impossibilidade de se atender às exigências impostas por uma lógica universal, que não leva em conta as particularidades. O tema da sexualidade se mostrou como outro impasse ao trabalho das professoras em sala de aula, em ambos os grupos. Disseram estar em fogo cruzado, e pontuaram as diferenças das crianças de hoje com as de antigamente no campo das manifestações sexuais. Neste momento de fulguração em que o tempo é igual a zero, não há um raciocínio ou subjetivação, apenas a constatação do que se pode ver. Assim, as professoras descreveram um cenário de grandes problemas, dos quais elas não tinham nenhuma participação, e que, como vítimas, sofriam passivamente. Eis então no instante do olhar "[...] o valor instantâneo de sua evidência" (Lacan, 1998, p. 204).

Constatamos, ainda, no primeiro semestre, uma coincidência das falas das professoras com relação aos principais impasses vivenciados

1112 Educação \& Realidade, Porto Alegre, v. 40, n. 4, p. 1103-1125, out./dez. 2015. 
em sua prática pedagógica, quais sejam: a família, a sexualidade e as políticas públicas educativas. As professoras se identificavam, entre si, através destes significantes, constituindo um grupo que as unificava, mas não as diferenciava.

\section{O Tempo de Compreender: os principais impasses na prática pedagógica}

Localizamos neste tempo lógico as conversações temáticas, quando as professoras começaram a se implicar em suas queixas, deslocando o problema, que inicialmente estava localizado fora delas, para a sua participação nele. Este tempo é o de formulação de uma hipótese e de meditação, quando, ao colocar-se no lugar dos outros, as professoras começam a refletir sobre as suas posições. Percebe-se, neste momento, o advento de falas que demarcam diferenciações entre as professoras no grupo, com a nomeação de uma dificuldade própria a cada uma. Veremos, a seguir, os desdobramentos das conversações no tempo de compreender, a partir dos três temas destacados.

\section{A Família}

Nos dois grupos, o tema da família foi o mais abordado pelas professoras. Elas responsabilizavam os pais pelos diversos comportamentos dos alunos. As educadoras procuravam explicar as deficiências dos alunos como sendo reflexos de famílias desestruturadas, marcadas por diversas faltas: de referências no lar, de harmonia entre o casal, de diálogos, falta de tempo e interesse destes no processo de aprendizagem dos filhos, ausência concreta de contato e omissão de responsabilidades.

O que as educadoras insistiam em denunciar é a existência de uma falha do pai em impor limites e uma falha da mãe nos cuidados básicos com os filhos. Assim, é a instituição escolar que é o lugar da regra, $e$, quando os alunos voltam das férias, é sempre um recomeço. Comparavam as mães atuais com as de antigamente, e afirmavam que a escola acaba entrando no lugar onde a família falta, os pais transferem para as educadoras as responsabilidades que são deles, estamos a todo o tempo apagando incêndio dos pais.

Qual a representação de família sustentada pelos discursos dos professores? Não é mesma da psicanálise. Em Nota sobre a criança, Lacan (2003) discorre sobre a função da família na estruturação da criança, distinguindo a função do pai da função materna. A função da mãe é a de transmitir um interesse particularizado pela criança, ou seja, através de seus cuidados ela evidencia sua condição de sujeito desejante. E a do pai, na medida em que seu nome é o vetor de uma encarnação da Lei no desejo, é a de figurar a lei sobre o desejo da criança e da mãe.

Educação \& Realidade, Porto Alegre, v. 40, n. 4, p. 1103-1125, out./dez. 2015.1113 
Psicanálise e Educação

Como salienta Couto (2012), diante da função simbólica da família de transmitir a castração, "[...] qualquer tentativa de explicação do fracasso escolar pela via das noções de carência afetiva, ausência dos pais, desestruturação da família, tomadas em seu caráter ambiental, torna-se insuficiente" (Couto, 2012, p. 92). Nesse sentido, é importante distinguir o pai da realidade do pai simbólico, já que mesmo que o primeiro esteja ausente, ou seja, distante do ideal social, é possível que haja a operação da inscrição do Nome-do-Pai no sujeito.

Lacan afirma que a função da família é residual, o que nos mostra que a transmissão se dá a despeito das mudanças ocorridas em sua configuração através dos tempos. Assim, o discurso que aponta uma relação direta entre fracasso escolar e família pode resultar em generalizações, impedindo que se perceba a possibilidade do fracasso escolar ser um sintoma da própria criança, ou seja, uma solução construída pelo sujeito.

A constituição subjetiva envolve operações de alienação e separação. Num primeiro momento, há uma alienação ao campo do Outro. A criança se aliena ao desejo do Outro. Em um segundo momento, há a separação do campo do Outro, com a possibilidade da criança colocar-se como um sujeito que também deseja. A separação ocorre no confronto com a falta do Outro, que remete o sujeito à própria castração. A dificuldade de aprendizagem pode ser resultado de um não querer saber da falta do Outro pela criança, ou seja, um não querer resultado da castração, condição para se constituir como um sujeito desejante. O sujeito precisa se responsabilizar pelo sintoma, única via possível de acesso ao desejo de saber.

Nas conversações, as intervenções foram feitas pelos coordenadores no sentido de desfazer mitos e significações cristalizadas, abrindo diferentes possibilidades de interpretação para uma mesma questão, a partir das diferentes versões apresentadas pelas professoras, dos equívocos e contradições surgidos em seus discursos. Assim, questionou-se o que elas construíram como verdade e que as mantinha numa posição de impotência.

Diante do impasse de não saber como intervir junto aos pais, as professoras se diziam impotentes. Esgotadas em suas possibilidades, lamentavam o fato: não temos dado conta; vai para além da função do educar. Tem hora que não dá para intervir mais. As queixas constantes das professoras revelaram uma angústia diante do excesso de atribuições que assumiam.

No grupo A, em uma das conversações, as professoras falaram sobre as dificuldades vivenciadas pela escola de acionar os pais para informá-los sobre os problemas de aprendizagem do filho. Como uma das saídas para esse impasse, elas criaram um projeto de reforço escolar ministrado por uma professora da própria escola. Elas disseram: tem que ter um olhar individual, porque se olhar igual para todo mundo não

1114 Educação \& Realidade, Porto Alegre, v. 40, n. 4, p. 1103-1125, out./dez. 2015. 
percebe certas coisas. Esta fala foi marcada pelo coordenador das conversações. Outra professora falou: não dá para tratar tudo no geralzão. Se não usarmos o particular, não chegaremos aos pais. Chegaram então à seguinte questão: Qual é o papel da escola diante dessa diversidade de famílias? Concluíram que, diante dessa diversidade, há um limite na atuação dos docentes. Finalizaram que seria importante pensar cada caso/aluno na sua particularidade, para então construir uma saída. Uma professora diz: o cuidado com o particular é necessário porque são alunos muito novos.

As educadoras passaram a falar sobre a importância de se considerar o particular de cada caso, evitando generalizações e classificações apressadas, reconhecendo que cada família é de um jeito. Concluíram que não é questão só de estrutura familiar, já que há famílias boas que têm filhos difíceis, exemplificando através do caso da família de um aluno cujo pai mexe com drogas e a mãe é doida, mas ele é um bom aluno, dedicado. Como pontuou o psicanalista que conduzia um dos grupos, a partir das falas das professoras, a família do aluno e o desempenho dele não estão sempre ligados.

Durante as discussões acerca do tema família, houve um deslocamento, da ênfase nos problemas familiares, para o trabalho possível com as crianças na escola. Uma professora disse: eu entendo os pais dos alunos de inclusão que não colocam limites, mas aqui não podemos deixar. Queríamos robozinhos, mas não tem jeito, não. Assim, elas percebem que é possível fazer o trabalho na escola com os alunos apesar de suas famílias.

As professoras começaram a utilizar aquele espaço para falar das próprias dificuldades, que designamos como o tempo de verificação, quando começaram a se implicar em suas queixas: A gente faz muita coisa com o coração, temos certeza que fazemos mais que nosso papel, a gente não consegue fazer menos. Em um dos encontros, no grupo A, uma professora disse: Aqui nós somos mãezonas. Ao que foi colocado: Pensávamos que eram professoras. Essa intervenção teve um efeito de corte nesse discurso da professora que se mantinha constante, provocando a resposta de outra participante: eu também!

Uma professora comentou: professor é tudo: é psicólogo, é médico, é tudo. Questionou-se se elas deveriam então trocar o nome professor para outro. Uma professora respondeu: para super... super... Outra interviu imediatamente: Não! É manter o nome de professor e empurrar as responsabilidades. Família é família, médico é médico. Uma terceira professora respondeu com um chiste: ela está na política do descarrego. Essa fala provocou riso de todos no grupo. Gradativamente, houve um deslocamento em relação a esse lugar de dar conta de tudo: Precisei dessa terapia para chegar à conclusão de que estou errada, dar conta de tudo é impossivel.

O corte é uma escansão. Produzido pelo coordenador das conversações ou por um membro do grupo, ele teve, por vezes, o efeito de um

Educação \& Realidade, Porto Alegre, v. 40, n. 4, p. 1103-1125, out./dez. 2015.1115 
ato, que se antecipa à sua certeza, que, por sua vez, se confirma numa precipitação lógica, como anuncia Lacan (1998). No tempo de compreender, "tempo de reflexão" (Lacan, 1998, p. 206), as professoras começaram a se implicar nesse acúmulo de funções que assumiam e no gozo que advinha dessa posição. Se todo sofrimento toca um ponto de gozo, cada uma pôde nomear o seu sofrimento de forma própria, localizando o que a incomodava no contato com as famílias dos alunos. Para uma, era a questão da sexualidade dos pais, para outra, a falta de zelo da mãe.

\section{A Sexualidade Infantil}

A sexualidade foi o segundo tema mais abordado pelas professoras. É cabível começar a discutir a temática da sexualidade a partir do seguinte adágio: Freud tinha razão, começamos pela sexualidade. Se a sexualidade surge com a linguagem, ela se faz presente desde os primórdios da vida da criança, ou melhor, antes mesmo do seu nascimento. Através da escuta das histéricas, Freud pôde reconhecer a existência de um psiquismo, com suas determinações inconscientes, outorgando a um conceito que já existia uma especificidade: o de ser um inconsciente regido pela pulsão sexual.

Em suas investigações na prática clínica sobre as causas e o funcionamento das neuroses, Freud dá à sexualidade o lugar de centralidade na vida psíquica. A experiência psicanalítica revelou o pluralismo dos componentes da sexualidade infantil, a partir do deslocamento da libido, ou seja, da energia da pulsão sexual, ao longo da vida dos sujeitos.

No entanto, apesar de estarmos em pleno século XXI, bem distantes do momento em que Freud postulou a existência da sexualidade infantil, as questões que envolvem o tema continuam a ser fonte de angústia, gerando mal-estar e constrangimentos nos adultos.

Desde o início do processo de socialização da criança, as questões sobre a sexualidade já aparecem em suas falas. A partir do direito assegurado pelo Estado de que toda criança deve frequentar a escola, esse fenômeno social, digamos sexual, adentra no contexto escolar, provocando uma série de desconfortos para a equipe educacional. Diante do exposto, assevera-se a importância da escola na transmissão de um trabalho educativo que abarque a sexualidade.

Freud (2006) destaca a existência da sexualidade infantil desde os primeiros meses de vida e comenta sobre o descaso para com a sua existência, mostrando que tal negligência é geradora de consequências graves, já que leva o adulto a tomar medidas repressoras e muitas vezes punitivas diante das manifestações sexuais da criança. A justificativa para se desconsiderar a existência da sexualidade infantil pelos adultos está no que Freud denominou amnésia infantil, pela qual a maioria das pessoas é submetida no período chamado latência; período este que marca a interrupção dos investimentos sexuais da criança pela intensificação do recalque, ocultando as lembranças da vida sexual na infância. Desta

1116 Educação \& Realidade, Porto Alegre, v. 40, n. 4, p. 1103-1125, out./dez. 2015. 
forma, o adulto é incapaz de lembrar de suas próprias experiências sexuais infantis, bem como reconhecer a existência da mesma.

Durante as conversações com as professoras, o tema da sexualidade infantil apareceu com frequência por meio de relatos das manifestações sexuais infantis na escola, tais como a curiosidade das crianças através de perguntas direcionadas a elas; bilhetinhos com conteúdos sexuais que circulavam entre os alunos; exibição dos órgãos genitais entre alunos; masturbação; etc. Os relatos vinham sempre acompanhados por certo espanto e até uma aparente surpresa diante da temática, como se ela fosse um mal atual, como pode ser verificado em algumas falas de uma professora bastante indignada: meus filhos não faziam isso, referindo-se às brincadeiras sexuais de algumas crianças da escola, ou, antes não se escutava sobre essas coisas cabeludas que escutamos hoje.

As professoras disseram que o tema da sexualidade gerava curiosidades nos alunos. Assim, elas propuseram aos alunos uma roda de conversa. Hoje em dia os meninos estão muito informatizados, eles sabem muita coisa que a gente, na nossa época, não tinha acesso. Imagina a gente na nossa época, com oito anos de idade, questionando o professor... Antes não podia falar. Mas consideraram o tema de difícil abordagem com os alunos: para você explicar a sexualidade de forma correta é muito difícil, porque muitos pais reclamam. É muito difícil explicar as coisas nessa idade.

É perceptível como o tema trazido pelas próprias crianças através de seus questionamentos, curiosidades e manifestações sexuais causa desconforto nas professoras, pois esbarra em conteúdos de ordem subjetiva que estão ligados aos próprios conteúdos sexuais que outrora foram recalcados, como nos mostrou Freud. Ou, de acordo com Lacan, o encontro com o sexo é sempre traumático, pois não existem palavras suficientes para nomeá-lo. A fala de uma professora ilustra isso: fico apavorada de ouvir essas coisas de crianças tão pequenas. As professoras se deparam com as próprias dificuldades em lidar com as situações cotidianas na escola relacionadas às vivências e manifestações sexuais dos alunos, alegando não saberem como agir ou responder ao que lhe são demandadas (Lima; Cunha, 2013). As iniciativas de ações por parte dos professores diante das manifestações da sexualidade infantil tendem a ser baseadas na punição, repressão, ocultamento ou negação, todas elas acarretando consequências de ordem psíquica que podem trazer prejuízos ao nível do funcionamento intelectual, como salienta Casarotti (2009).

A metodologia da conversação propicia um espaço onde a equipe pedagógica pode falar e refletir acerca de temas que assombram o contexto escolar e que lhes assombram, de forma particular, como a sexualidade. Uma professora reconhece a sua fantasia de que a pedofilia está sempre muito próxima, que resulta em interrogatórios constantes dirigidos às crianças na escola sobre a sexualidade dos pais. As professoras passaram a falar sobre as suas próprias dificuldades com relação

Educação \& Realidade, Porto Alegre, v. 40, n. 4, p. 1103-1125, out./dez. 2015.1117 
Psicanálise e Educação

ao tema da sexualidade, deslocando, assim, da ênfase no aluno para as próprias dificuldades. Uma delas colocou: a aluna chega igual uma periguete, com batom vermelho e blush, igual uma mocinha. Quando foi interrogada sobre o motivo do incômodo que a aluna lhe causava, a professora concluiu que ela tinha dificuldades para lidar com a questão da sexualidade dos alunos. Outra professora, ao dizer da sua dificuldade em lidar com os alunos da inclusão, afirma: todas aqui querem mostrar que dão conta, mas acho que todas têm deficiências, lidar com a diferença é muito bom, mas é sofrido.

Mas, as conversações também possibilitaram o surgimento de opiniões consensuais e a tomada de decisões coletivas. Como exemplo, as professoras perceberam a importância de se estabelecer limites para as manifestações de sexualidade que não podem ocorrer no espaço público, permitindo, entretanto, a livre manifestação dos questionamentos das crianças, reconhecendo o mal-estar como parte integrante de todo processo educativo. As professoras chegaram a um acordo sobre a importância de se permitir que as crianças construam as suas próprias representações sobre a sexualidade.

Nas conversações seguintes, as falas das professoras apontavam para uma diminuição da angústia. No grupo A, uma professora coloca, a respeito do tema da sexualidade: Acho que por agora esse tema deu uma tranquilizada. Eles estavam mais agitados no primeiro semestre. Acho que eles amadureceram também. Complementaram: Acho que o professor precisa mais ouvir do que falar, se precisar esclarecer algo, a gente faz a intervenção. Finalizaram a conversação dizendo: a gente tem que ser flexível né, tanto com os alunos bons, quanto com os outros.

\section{As Políticas Públicas de Educação}

O tema das políticas públicas no campo da educação foi o terceiro mais presente nas falas das professoras. Elas ressaltaram de que forma as políticas públicas repercutiam na organização de seus trabalhos, por exemplo, no planejamento das aulas, no cumprimento das metas e no dia-a-dia de sala de aula. Os tópicos das políticas públicas que mais interferem em seus trabalhos, segundo as professoras, são: Inclusão, Escola Aberta, Política e Avaliação. Eles geram impasses em seus trabalhos pedagógicos, uma vez que despertam nelas um sentimento de que deveriam dar conta de tudo.

As educadoras afirmaram que o professor, por trabalhar com o modelo de avaliação onde o erro é punido, apresenta dificuldades em aceitar os próprios erros. Por sua vez, ele se sente a cada dia mais cobrado, tendo que cumprir metas rígidas no aprendizado das crianças. Acompanha-se, no campo das políticas públicas educacionais, um sistema cada vez mais burocrático, técnico e avaliativo. As queixas foram constantes em relação ao volume de trabalho, resultado de um acúmulo de funções assumido pelo professor.

1118 Educação \& Realidade, Porto Alegre, v. 40, n. 4, p. 1103-1125, out./dez. 2015. 
Há aqui a predominância do discurso do Mestre, pois o professor sustenta esse lugar, numa promessa de que é possível dar conta de tudo, ou seja, as professoras defendem um saber total, sem furos: temos que dar conta de tudo, somos mãezonas. O significante precariedade surgiu para designar tudo aquilo, que segundo as professoras, faltava nas crianças ou na família, nos planos econômico e afetivo, o que justificava as suas condutas protetoras. Segundo elas: aumentou o cuidado do Estado, aumentou o desleixo dos pais, Escola é um lugar de tudo: escovação, saúde. É tudo dentro da escola. No entanto, as professoras sentiam-se angustiadas diante dessa carga assumida pela escola, afirmando que não eram escutadas pelos gestores, somente cobradas em relação aos resultados.

As professoras falavam também das dificuldades que encontravam no processo de inclusão escolar dos alunos especiais, que, segundo elas, deveriam ficar separados dos alunos regulares, em atividades fora da sala. Paradoxalmente, acreditavam que o aluno tem que ficar dentro da sala, apesar das diferenças, todos tem que ser tratados como iguais.

O discurso universitário também se fez presente nas falas das professoras a partir da importância dada aos diagnósticos médicos na abordagem pedagógica dos alunos de inclusão. Da mesma forma, as professoras demandavam, dos psicólogos, laudos psicológicos, para que pudessem compreender as causas dos distúrbios das crianças que apresentavam dificuldades comportamentais. Essa demanda, insistente no início das conversações, praticamente desapareceu com o prosseguimento dos encontros, com o deslocamento progressivo do interesse pelas causas do problema para o interesse nas suas soluções, nas invenções ou saídas construídas por elas diante dos problemas apresentados pelos alunos. Concordamos com Cohen (2006) quando afirma que há sempre algo de indecidível no fracasso escolar, ou seja, sua etiologia sempre é parte de uma determinada contingência educacional, assim não há uma verdade generalizável que explique sua manifestação em todos os alunos que o experimentam.

Além das dificuldades pedagógicas dos alunos de inclusão, como eram por elas designados, as professoras também abordaram as dificuldades dos pais em aceitarem ou perceberem a diferença dos seus filhos. Uma professora relata um caso de aluno que em dois meses em sala de aula, melhorou pedagogicamente, deu um salto. Consideraram que os três anos vividos na escola mudaram a vida dele, sendo um efeito da teimosia das professoras. Complementaram: porque se tivéssemos ouvido a mãe, teríamos desistido deste aluno. Este investimento dos professores foi marcado pelo coordenador das conversações, com o objetivo de acentuar a importância de se acreditar no aluno, além de valorizar a implicação do desejo do professor na prática pedagógica, permitindo que elas saíssem da posição de impotência diante das dificuldades escolares. 
Psicanálise e Educação

As professoras descrevem um cenário que caracteriza a crise da educação na atualidade, que, entretanto, tem sua origem na modernidade. Arendt (2013) relaciona a crise da educação com a crise da autoridade na modernidade. Ela defende que a criança localiza-se num lugar de submissão extrema ao mundo dos adultos, é de responsabilidade dos adultos cuidar do processo de vir a ser das crianças. Na modernidade, a criança é emancipada face à autoridade dos adultos. Mas, a criança não foi liberta, mas antes submetida a uma autoridade muito mais feroz e verdadeiramente tirânica: a tirania da maioria. Elas ficam, ou entregues a si mesmas, ou à tirania do seu grupo, grupo contra o qual, tendo em vista a sua superioridade numérica, não podem se revoltar.

A autora enfatiza que em toda crise de um sistema de educação, deve-se pensar qual a função da educação das crianças e qual o papel que ela desempenha em cada civilização. Qual o lugar ocupado pela criança no projeto de civilização? Qual é a função dos adultos na introdução das crianças na esfera pública? Para Arendt (2013), o estreitamento dos limites entre a vida privada, a vida em família, e a vida pública, a escola e o mundo, configura um abandono às crianças, uma vez que o papel da escola deveria ser o de apresentar às crianças a esfera pública, o mundo, facilitando as condições para que as características individuais de cada um possam ser exercidas nessa esfera pública. Ao contrário disso, a educação atual passa a representar, através da escola, uma instituição de reprodução do mundo em crise, com pouco espaço para a participação das crianças na construção de um novo futuro.

As professoras queixaram-se de que as políticas educativas forçam um modelo de educação que reproduz as condições que levam ao fracasso escolar, por não darem espaço para as vivências em sala de aula, e concluíram que os professores não são escutados em relação à sua prática docente.

O tema das políticas públicas foi gradativamente deslocado, das queixas para as soluções que elas construíam para lidar com os impasses vivenciados. Questionou-se, então, que, apesar das exigências burocráticas, algumas coisas que elas faziam davam certo. Ao que uma das professoras colocou: A gente quer fazer direito, se a gente fosse fazer a ferro e fogo a escola não andava. Muito do que dá certo são coisas que a gente mesmo faz. De uma parte dos pais a gente tem um feedback bom, porque a gente trabalha bem.

As professoras deixaram de se queixar das exigências que lhes eram impostas e começaram a falar daquelas que elas mesmas se impunham. Além disso, a rigidez das políticas educativas passou a ser relativizada, na medida em que elas começaram a falar sobre as saídas encontradas para ajustar as regras universais às especificidades da escola e de cada aluno.

Se o tema das políticas públicas foi comum a todas, ou seja, foi um dos significantes que as agrupou, a forma como cada professora se

1120 Educação \& Realidade, Porto Alegre, v. 40, n. 4, p. 1103-1125, out./dez. 2015. 
dizia afetada por essas mesmas políticas apontou as diferenças entre elas. A suposição de saber inicialmente endereçada ao coordenador das conversações foi reenviada a cada uma, permitindo a construção de um saber próprio, distinto dos demais do grupo. Assim, surgiram diferenças com relação à forma de interpretação das políticas públicas, às exigências que afetavam cada professora e à maneira de responder a essas exigências.

\section{Momento de Concluir}

A análise do material nos levou a buscar localizar três tempos lógicos que se sobressaíram nas conversações. Designamos como o instante de olhar o momento em que as professoras utilizaram esse espaço para falar de suas insatisfações, responsabilizando o Outro pelos seus sofrimentos. Criaram um cenário de grandes problemas, sem se implicarem nele. Destaca-se, nesse tempo lógico, a percepção daquilo que convém ao eu. Designamos como o tempo de compreender aquele em que as professoras começaram a se implicar em suas queixas, responsabilizando-se pelos problemas inicialmente percebidos como exteriores a elas. As diferenciações começaram a surgir no grupo, que deixou de ser sustentado pela coesão ou pela identidade imaginária. Com o prosseguimento das conversações, percebemos a diminuição das queixas relativas aos alunos, aos pais ou ao Município. Para Lacan (1998), o momento de concluir é captado pelo sujeito ante a evidência subjetiva de um tempo de demora que o apressa em direção à saída. O juízo assertivo manifesta-se aqui por um ato. Destacamos, nas cadeias discursivas impulsionadas pela associação livre, intervenções do coordenador ou de um participante da conversação que operaram como um corte na cadeia, interrompendo-a, promovendo uma descontinuidade discursiva. Lacan (1998) destaca que o que constitui a singularidade do ato de concluir "é que ele se antecipa à certeza, em razão da tensão temporal de que é subjetivamente carregado, e que, sob a condição dessa mesma antecipação, sua certeza se confirma numa precipitação lógica que determina a descarga dessa tensão, para que a conclusão fundamente-se em instâncias temporais objetivadas" (Lacan, 1998, p. 209). Assim, o tempo subjetivo do momento de concluir objetiva-se. Destacamos, nesse tempo lógico, o corte na cadeia associativa, que possibilitou uma mudança na estrutura do discurso das professoras, efeito que, mesmo que provisório, provocou o deslocamento da ênfase nos problemas para as soluções.

A última conversação permitiu colher alguns efeitos das conversações durante o ano nas falas das professoras. Nos dois grupos, as professoras ressaltaram a importância do espaço para a palavra. No grupo A, uma professora falou sobre a importância dos encontros, pois nos últimos tempos elas não estavam se encontrando para conversar sobre os alunos, as aulas e os problemas vivenciados nos seus trabalhos.

Educação \& Realidade, Porto Alegre, v. 40, n. 4, p. 1103-1125, out./dez. 2015.1121 
Uma delas comentou que gostaria que as reuniões pedagógicas fossem daquela maneira, sem nenhuma distinção entre a coordenadora e as demais professoras. No grupo $\mathrm{B}$, uma das participantes disse: as expectativas eram diferentes em relação ao trabalho. Esperava o atendimento de todos os alunos e ficava angustiada de ver que eles não estavam sendo atendidos. Outra professora disse que tinha uma expectativa diferente no início do trabalho, mas que ao longo das conversações percebeu que aquele era um trabalho do grupo e que era difícil se expor, mostrar que ela pensava diferente das outras colegas de trabalho. E concluiu foi bom para as outras saberem das diferenças e respeitá-las. Uma professora do grupo A disse: Eu estava esperando que você (se dirigindo ao psicanalista que conduziu as conversações) fosse dar uma resposta às nossas dúvidas, e você fez a gente pensar. Outra participante disse: conversar em grupo diminuiu a angústia de não saber lidar com a família.

Destacamos três principais efeitos das conversações. Em primeiro lugar, a mudança de posição, da impotência à impossibilidade, percebida especialmente no grupo A. As professoras chegaram à conclusão de que a angústia em relação ao tratamento dos alunos e aos temas discutidos diminuiu muito, pois foi possível perceber os limites do professor. Com isso, se sentiram mais dispostas ao trabalho, dentro das suas possibilidades. Algumas saídas próprias, construídas pelas professoras diante dos desafios encontrados na transmissão pedagógica, foram compartilhadas no grupo.

Em segundo lugar, a abertura de novos espaços para a palavra na instituição. As professoras do grupo B iniciaram um encontro entre elas, mensal, para conversar sobre as dificuldades enfrentadas em suas práticas docentes. Além disso, as professoras relataram iniciativas que elas tomaram no sentido de escutar os alunos, através, por exemplo, de rodas de conversas.

Em terceiro lugar, localizamos o surgimento das diferenças no espaço coletivo, que foi suportada e respeitada pelos membros do grupo. Algumas professoras puderam nomear o seu sofrimento, de forma particular. Se para uma delas o mais difícil era lidar com a questão da sexualidade do aluno, para outra era lidar com a família. Uma professora ressaltou que o seu maior desafio era enfrentar a não-aprendizagem da criança. Nesse enlace do gozo à palavra, pode surgir a possibilidade de um saber-fazer com isso.

Recebido em 15 de fevereiro de 2014 Aprovado em 24 de dezembro de 2014

\section{Notas}

1 Para abordar a realidade psíquica, Lacan construiu a tríade Simbólico, Imaginário e Real. O real se caracteriza pela ex-sistência aos registros imaginário e simbólico, discernido pela modalidade lógica do impossível.

1122 Educação \& Realidade, Porto Alegre, v. 40, n. 4, p. 1103-1125, out./dez. 2015. 
2 Lacan apresenta várias versões do gozo em seu ensino. O gozo na teoria lacaniana relaciona-se com a dimensão que vai além do princípio do prazer, com a pulsão de morte, descrita por Freud. Em 1966, Lacan destaca que o gozo, no sentido daquilo que o corpo experimenta, é sempre da ordem da tensão, do forçamento, do gasto, inclusive da proeza, até no nível da dor. O gozo é o obscuro núcleo do nosso ser. O gozo é um excesso, um buraco no simbólico, um topos inacessível para o sujeito que o aloja. No Seminário 20, ao retomar a concepção jurídica do termo gozo, Lacan afirma que ele é singular, diferentemente do desejo que é universal. Enquanto o desejo vem do Outro, o gozo está do lado do Um, que aponta para o que há de mais singular no sujeito (Braunstein, 2007).

3 Para Lacan, uma vez que toda relação é permeada pela linguagem, os laços sociais se estabelecem a partir de discursos. Lacan nomeou quatro discursos, que estruturam os laços sociais e a nossa civilização: histérico, do Mestre, universitário e do analista. $O$ discurso como laço social é um modo de aparelhar o gozo com a linguagem (Quinet, 2006).

4 Para abordar a realidade psíquica, Lacan construiu a tríade Simbólico, Imaginário e Real. O real se caracteriza pela ex-sistência aos registros imaginário e simbólico, discernido pela modalidade lógica do impossível.

\section{Referências}

ARENDT, Hannah. A Crise na Educação. Entre o Passado e o Futuro. São Paulo: Perspectiva, 2013. P. 221-247.

BESSET, Vera Lopes; RUBIM, Luiza Mendes. Psicanálise e Educação: desafios e perpectivas. Estilos da Clínica, São Paulo, v. 12, n. 23, dez. 2007. Disponível em: <http://pepsic.bvsalud.org/scielo.php?pid=S1415$-71282007000200004 \&$ script=sci_arttex>. Acesso em: 12 jan. 2014.

BRAUNSTEIN, Nestor. Gozo. São Paulo: Escuta, 2007.

CASAROTTI, Magda Helena Balbino. Sexualidade na Educação Infantil: impasses dos professores diante das questões das crianças. 2009. 143f. Dissertação (Mestrado em Educação) - Faculdade de Educação, Universidade Federal de Santa Maria, Santa Maria, 2009.

COHEN, Ruth Helena Pinto. A Lógica do Fracasso Escolar: psicanálise e educação. Rio de Janeiro: Contra Capa Livraria, 2006.

COUTINHO, Luciana Gageiro; ROCHA, Ana Paula Rangel. Grupos de Reflexão com Adolescentes: elementos para uma escuta psicanalítica na escola. Psicologia Clínica, Rio de Janeiro, v. 19, n. 2, p. 71-85, 2007. Disponível em: <http:// www.scielo.br/scielo.php?script=sci_arttext\&pid=S0103-56652007000200006 >. Acesso em: 15 fev. 2014

COUTO, Margarete Pires do. O Fracasso Escolar e a Família: o que a clínica ensina? Belo Horizonte: Scriptum, 2012.

FERREIRA, Tânia. Freud e o Ato do Ensino. In: LOPES, Eliana Marta Teixeira (Org.). A Psicanálise Escuta a Educação. Belo Horizonte: Autêntica, 1998. P. 107150.

FREUD, Sigmund. Três Ensaios sobre a Teoria da Sexualidade. In: FREUD, Sigmund. Um Caso de Histeria; Três Ensaios sobre a Teoria da Sexualidade e outros Trabalhos. Rio de Janeiro: Imago, 2006.

LACADÉE, Philippe. Da Norma da Conversação ao Detalhe da Conversação. In: LACADÉE, Philippe; MONIER, Françoise (Org.). Le Pari de la Conversation.

Educação \& Realidade, Porto Alegre, v. 40, n. 4, p. 1103-1125, out./dez. 2015.1123 
Institut du Champs Freudien: cien centre interdisciplinaire su l'enfant. Paris, 2000. P. 1-4.

LACAN, Jacques. O Tempo Lógico e a Asserção de Certeza Antecipada. In: LACAN, Jacques. Escritos. Rio de Janeiro: Zahar, 1998. P. 197-213.

LACAN, Jacques. Nota sobre a Criança. In: LACAN, Jacques. Outros Escritos. Rio de Janeiro: Zahar, 2003. P. 369-370.

LACAN, Jacques. O Seminário, livro 17: o avesso da psicanálise. Rio de Janeiro: Zahar, 1992

LAURENT, Eric. A Crise do Controle da Infância. In: BRISSET, Fernanda Otoni; SANTIAGO, Ana Lydia; MILLER, Judith (Org.). Crianças Falam! E Têm o que Dizer. Experiências do Cien no Brasil. Belo Horizonte: Scriptum, 2013. P. 25-36.

LIMA, Nádia Laguárdia; CUNHA, Cristiane de Freitas. A Escuta de Adolescentes na Escola: a sexualidade como um sintoma escolar. Revista Estilos da Clínica, São Paulo, v. 18, n. 3, dez. 2013. Disponível em: <http://pepsic.bvsalud.org/scielo.php?pid=S1415-71282013000300005\&script=sci_arttext $>$. Acesso em: $03 \mathrm{dez}$ 2013.

MILLER, Jacques-Alain A. A Conversaç̃o - Abertura da Discussão. In: Os Casos Raros, Inclassificáveis, da Clínica Psicanalítica - A Conversação de Arcachon. São Paulo: Biblioteca Freudiana Brasileira, 1998. P. 103-187.

MILLER, Jacques-Alain A. La Práctica de la Conversación. In: MILLER, Jacques Alain. Conferências Porteñas. Buenos Aires: Paidós, 2010. P. 87-91.

PEREIRA, Marcelo Ricardo. A Orientação Clínica como Questão de Método à Psicologia, Psicanálise e Educação. In: PEREIRA, Marcelo R. (Org.). A Psicanálise Escuta a Educação 10 Anos Depois. Belo Horizonte: Fino Traço, 2012. P. 23-34. QUINET, Antônio. Psicose e Laço Social: esquizofrenia, paranoia e melancolia. Rio de Janeiro: Jorge Zahar Ed., 2006.

ROSA, Miriam Debieux. A Pesquisa Psicanalítica dos Fenômenos Sociais e Políticos: metodologia e fundamentação teórica. Revista Mal-estar e Subjetividades, Fortaleza, v. 4, n. 2, p. 329-348, 2004. Disponível em: <http://pepsic.bvsalud.org/pdf/malestar/v4n2/08.pdf>. Acesso em: 15 fev. 2014.

SANTIAGO, Ana Lydia; VASCONCELOS, Renata Nunes; MIRANDA, Margarete Parreira. Pesquisa em Psicanálise e Educação: a conversação como metodologia de pesquisa. In: PSICANALISE, EDUCACAO E TRANSMISSAO, 6., 2006, São Paulo. Proceedings online... São Paulo, 2006. Disponível em: <http://www. proceedings.scielo.br/scielo.php?pid=MSC0000000032006000100060\&script=s ci_arttext>. Acesso em: 15 fev. 2014.

UDENIO, Beatriz. El Cien: un uso del psicoanálisis del que hay que rendir cuenta. Cuadernos del CIEN, Instituto del campo freudiano, Buenos Aires, CIEN Instituto del campo freudiano; Centro de investigaciones del ICBA, p. 61-70, nov. 2004 .

1124 Educação \& Realidade, Porto Alegre, v. 40, n. 4, p. 1103-1125, out./dez. 2015. 
Nádia Laguárdia de Lima é doutora em Educação, pós-doutoranda em Teoria Psicanalítica pela UFRJ, professora do Programa de Pós-Graduação e do Departamento de Psicologia da UFMG.

E-mail: nadia.laguardia@gmail.com

Ronaldo Sales de Araújo é psicólogo pela PUC Minas BH, mestre em Psicologia pela UFMG, psicólogo Clínico da Fundação Hospitalar do Estado de Minas Gerais (FHEMIG).

E-mail: rsales.psi@gmail.com

Eduardo Pio de Souza é psicólogo pela PUC Minas BH, mestre em Psicologia pela UFMG.

E-mail:piodesouza@yahoo.com.br

Allana Fernanda Gonçalves Dias é psicóloga pela UFMG.

E-mail: allanamanda@hotmail.com

Carolina Albuquerque Barbosa é psicóloga pela UFMG.

E-mail: carolignana@gmail.com

Raquel Gonçalves Silveira Alves é psicóloga pela UFMG.

E-mail: raquelalves03@gmail.com

Karina Maciel Nihari é graduanda em Psicologia pela UFMG.

E-mail: karinanihari@gmail.com

Nayara Serrano Barcelos Marchi é graduanda em Psicologia pela UFMG.

E-mail: nayaraserrano@hotmail.com 